\title{
Antigen Epitope Developed Based on Acinetobacter baumannii MacB Protein Can Provide Partial Immune Protection in Mice
}

\author{
Xiaojie Song $\mathbb{D},{ }^{1}$ Guanghui Zhao $\mathbb{D}^{2},{ }^{2}$ and Meiling Ding $\mathbb{C}^{1}$ \\ ${ }^{1}$ Department of Respiratory Medicine, Qilu Hospital of Shandong University, Qingdao, China \\ ${ }^{2}$ Blood Transfusion Department, Qilu Hospital of Shandong University, Qingdao, China \\ Correspondence should be addressed to Meiling Ding; 18561811909@163.com
}

Received 16 March 2020; Revised 30 July 2020; Accepted 11 August 2020; Published 20 October 2020

Academic Editor: Ruxana Sadikot

Copyright (C) 2020 Xiaojie Song et al. This is an open access article distributed under the Creative Commons Attribution License, which permits unrestricted use, distribution, and reproduction in any medium, provided the original work is properly cited.

\begin{abstract}
Acinetobacter baumannii (A. baumannii) is an important opportunistic pathogen widely present in medical environment. Given its complex drug resistance, $A$. baumannii poses a serious threat to the safety of critically ill patients. Given the limited alternative antibiotics, nonantibiotic-based functional anti-A. baumannii infection proteins must be developed. In this study, we firstly used a series of biological software to predict potential epitopes in the MacB protein sequence and verified them by antibody recognition and lymphocyte proliferation tests. We finally screened out B cell epitope $2, \mathrm{CD} 8^{+} \mathrm{T}$ cell epitope 7 , and $\mathrm{CD} 4^{+} \mathrm{T}$ cell epitope 11 and connected them to construct a recombinant antigen epitope (RAE). The determination of IgG in the serum of immunised mice and cytokines in the supernatant of lymphocytes showed that the constructed epitope induced an immune response mediated by Th-1 cells. Finally, the challenge experiment of A. baumannii infection in mice confirmed that the epitope developed based on $\mathrm{MacB}$, especially RAE, provided incomplete immune protection for mice.
\end{abstract}

\section{Introduction}

Acinetobacter baumannii (A. baumannii, $\mathrm{Ab}$ ) is an important opportunistic pathogen in clinical environment [1]. The bacterium is widely distributed in hospital environments and can survive for a long time in specific departments, such as intensive care units [2], neurosurgery [3], and respiratory medicine [4], easily causing infection in critically ill patients. A. baumannii mainly causes respiratory tract infection [5], but it can also cause bacteraemia [6], urinary tract infection [7], secondary meningitis, and surgical site infection $[8,9]$.

A. baumannii is the most common pathogen isolated from patients with hospital-acquired pneumonia in thirdgrade class-A hospitals in China, and hydrocarbon-resistant strains (CR-Ab) account for $60 \%$ to $70 \%$ [10]. The drug resistance of A. baumannii has become a global challenge [11]; $\mathrm{CR}-\mathrm{Ab}$ tops the World Health Organization's list of pathogens in need of new antibiotics [12]. In the presence of CR$\mathrm{Ab}$, when clinicians use high-level antibiotics, such as tetracycline and polymyxin, the treatment effect is occasionally unsatisfactory [13]. This condition also causes heavy financial burden to patients and harmful drug side effects caused. The bacteriostatic or bactericidal strategy based on nonantibiotics is a promising research direction. The outer membrane proteins play an important role in the survival and pathogenesis of $A$. baumannii [14]. MacAB-TolC is an $\mathrm{ABC}$ type efflux pump responsible for conferring resistance in bacteria to several antibiotics, while macB was observed to be an essential controlling hub of the network and played a crucial role in MacAB-TolC efflux pump. MacB can act as a potential drug target for successful treatment strategies in Salmonella enterica serovar Typhi CT18 [15]. Molecular docking studies of the efflux pump MacB protein revealed that the EPI compound MC207-110 presented a higher binding affinity towards $\mathrm{MacB}$ protein. It also can serve as a possible drug target in drug development and discovery [16]. A series of structures of full-length MacB have helped reveal molecular details of its operation. MacB from A. baumannii was crystallized in ADP-bound form [17]. This study is aimed at observing the effect of MacB protein on A. baumannii by inhibiting its activity. 


\begin{tabular}{|c|c|c|c|c|}
\hline \multicolumn{5}{|c|}{ Unconserved 01123445678910 Conserved } \\
\hline $\mathrm{MacB}$ & МнНнННHMTK QALLEVSNLV & REFPAGESTI & QILKGIDITI & YEGELVAIVG \\
\hline Consistency & $09 * * \quad * * * * * * * * * 9$ & $\star * * * * * * 9 * *$ & $\star \star \star \star * * \star \star \star * \star *$ & 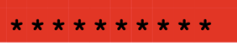 \\
\hline & $60 \ldots \ldots 70$ & $\ldots \ldots 80$ & . 90 & 100 \\
\hline $\mathrm{MacB}$ & QSGSGKSTLM NILGCLDRPT & SGSYKVNGQE & TGKLEPDQLA & QLRREYFGF I \\
\hline Consistency & 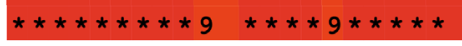 & $9 * * * * * 9 * 9 *$ & 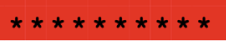 & $7 * * * * * * * * *$ \\
\hline & $110 \ldots$ & 130 & 14 & 150 \\
\hline $\mathrm{MacB}$ & FQRYHLLGDL SAEGNVEVPA & VYAGVTPADR & KQRATALLTE & L GLGTKTQNR \\
\hline Consistency & $\star * * * * * * * * * \quad * * * 9 * * * * * *$ & $* * * 9 * 9 * 88 *$ & $* * * * * * * * * 9$ & $* \star * * * * \star 69 *$ \\
\hline
\end{tabular}

\begin{tabular}{|c|c|c|c|c|}
\hline \multirow[b]{2}{*}{ MacB } & \multicolumn{4}{|c|}{$160 \ldots \ldots \ldots 170 \ldots \ldots \ldots 180 \ldots \ldots \ldots$} \\
\hline & P SQLSGGQQQ RVSIARALMN & GGDVILADEP & TGALDSHSGV & EVMRILRELN \\
\hline y & 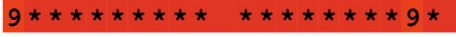 & *** & $* 299 * 9$ & $\star \star 9 * \star \star \star 9 * \star$ \\
\hline & 210 & & & \\
\hline IacB & I LVT HD & I SDGEI & 'PDQ & DPD \\
\hline onsi & $\star \star 9 * * 9 * * \star *$ & $\star \star \star \star * \star * \star * \star * a 9$ & $\star \star \star \star \star \star \star \star ~ * 9999$ & 7696998999 \\
\hline
\end{tabular}

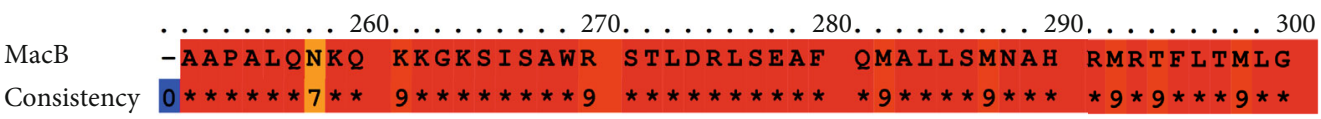

\begin{tabular}{|c|c|c|c|c|}
\hline \multirow[b]{2}{*}{$\mathrm{MacB}$} & \multirow{2}{*}{\multicolumn{4}{|c|}{$\begin{array}{l}\ldots \ldots \ldots 310 \ldots \ldots \ldots \\
\text { IIIGIASVVT }\end{array}$}} \\
\hline & & & & \\
\hline \multirow[t]{2}{*}{ Consistency } & 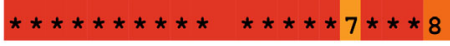 & $\star \star * 8 * * * 8 * *$ & $* * * * \star 9 * * * 9$ & $\star \star \star \star \star 9 * \star \star 997$ \\
\hline & $360 \ldots$ & 380 & .39 & $0 \ldots$ \\
\hline $\mathrm{MacB}$ & FKTLVPADAD ALMTQPYVSA & VSPMVSTSKT & MRYQQNEANA & TINGVSNDYF \\
\hline \multirow[t]{2}{*}{ Consistency } & 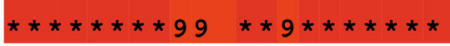 & $\star \star \star 8 * 9 * \star \star \star$ & 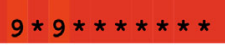 & $\star * \star * * * * * 9 *$ \\
\hline & 410 & 430 & 44 & 0. \\
\hline $\mathrm{MacB}$ & DVKGLVFKDG QTFDQRSVRD & RSQDVVIDTN & TQKQFF SDGT & NP I GQVVLIG \\
\hline Consistency & 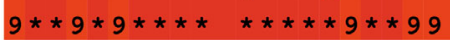 & 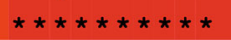 & $\star 9 * \star \star \star 99 * 9$ & 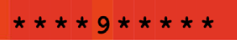 \\
\hline
\end{tabular}

\begin{tabular}{|c|c|c|c|c|}
\hline \multirow{2}{*}{$\mathrm{MacB}$} & \multicolumn{4}{|c|}{ 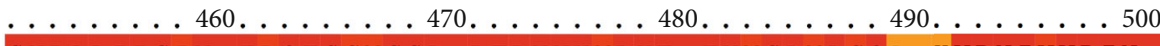 } \\
\hline & VPARIIGIV EPQTSGMGSD & DTLNVYMPYT & TVMSRMLGQA & $\mathrm{HV}$ \\
\hline & $\star \star * \star * * * 9 * \quad * 9 * * \star 99 * * *$ & $\star \star \star \star \star * \star 2,9 * *$ & $* \star 9 * * 9 * 9 *$ & $7 * \star \star \star * 9 * \star$ \\
\hline
\end{tabular}

\begin{tabular}{|c|c|c|c|c|c|}
\hline MacB & DKYSTSAAEN & A I VNLLTQRH & GAQDIFTMNS & D S IRQTIEKT & TSTMTLIVSA \\
\hline ncy & $* 9 * * * 7 * * * *$ & $\star * a * * * * * * *$ & $\star \star \star \star \star \star * \star * 9 * *$ & $\star \star \star * \star * * 9 * \star *$ & $\star 9 * 9 * * * * * *$ \\
\hline
\end{tabular}

\begin{tabular}{|c|c|c|c|c|}
\hline \multirow[b]{2}{*}{$\mathrm{MacF}$} & \multicolumn{4}{|c|}{$560 \ldots \ldots \ldots$. . $570 \ldots \ldots \ldots$. . $580 \ldots \ldots \ldots$. } \\
\hline & ILVS & E I GV & RQSD & I L \\
\hline & $\star \star 99 * \star 9 * \star \star$ & 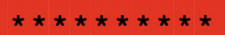 & 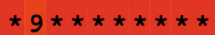 & $* * * * * * * * * *$ \\
\hline
\end{tabular}

\begin{tabular}{|c|c|c|c|}
\hline MacB & $\begin{array}{l}\ldots \ldots \\
\text { LVCLIGGVLG VILSLGLGQL INKFAGGNFA }\end{array}$ & VAYSTTSIVA & AFVCSTLIGV \\
\hline Consistency & $\star * * * * 9 * 9 * * \quad * * * * * * * * * 9 \quad * * * 8 * 8 * * * 8$ & $* * * * 8 * * * 99$ & $* * * * * * * * * *$ \\
\hline & 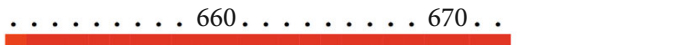 & & \\
\hline MacB & VFGFLPAKNA AKLDPVAALS RE & & \\
\hline Consistency & 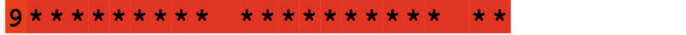 & & \\
\hline
\end{tabular}

Figure 1: MacB sequence homology with 99 sequences obtained from protein BLAST against Acinetobacter. The superposition was performed with the PRALINE programme and adjusted manually. Residue conservation is depicted by blue to red colours. 


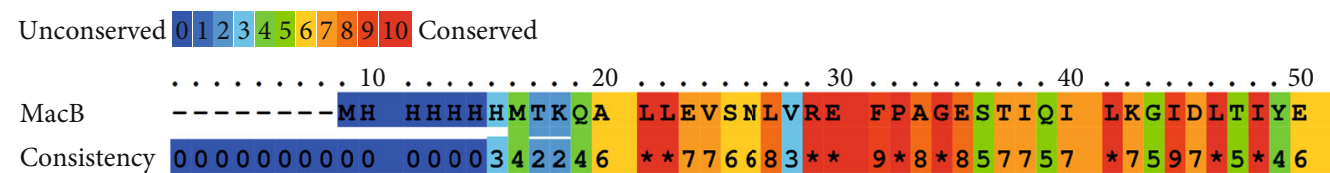

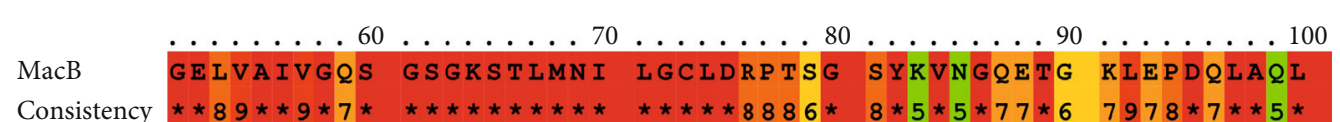

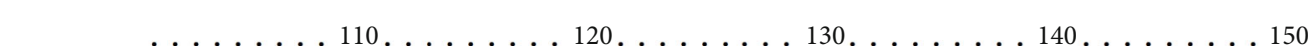
MacB RREYFGEIFQ RYHLGDLSA EGNVEVAVY AGVTPADRKQ RATALTELG

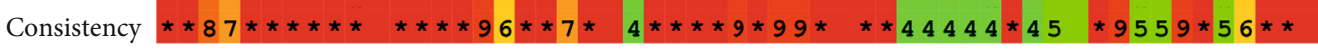

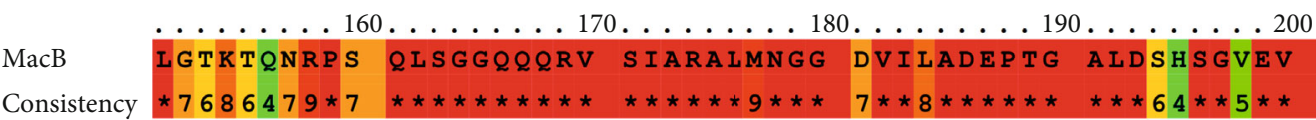

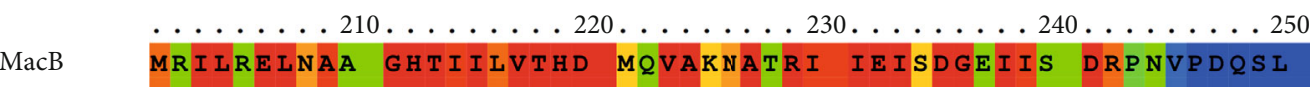
Consistency $85 * * 5 * * 795 * * * 9 * 8 * * * * 65 * 67 * 5 * 9 * * * 6 * * 5 * 95 * 845100000$

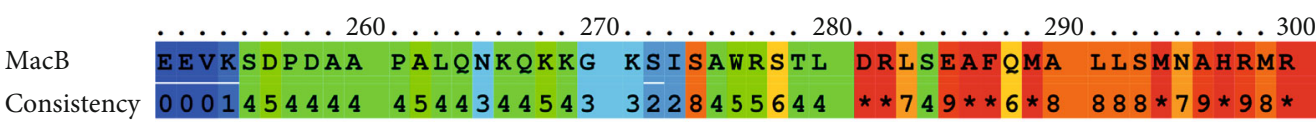

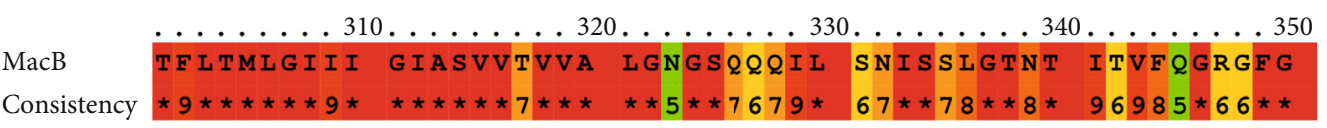

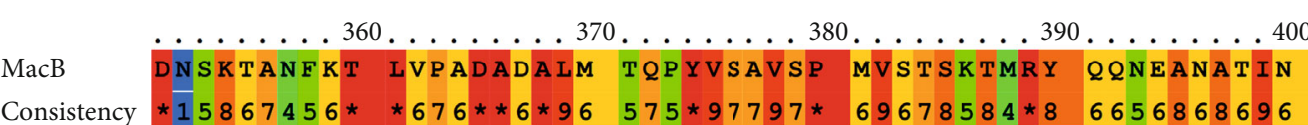

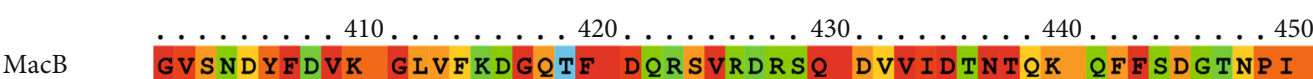

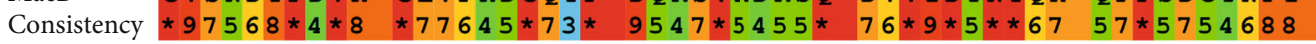

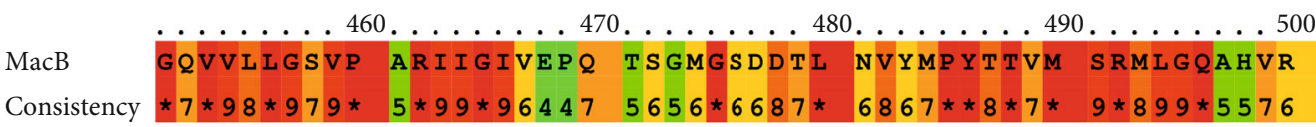
$\begin{array}{ll}\text { MacB } & \ldots \ldots \ldots \\ \text { NIVVRINDKY STSAAENAIV NLITQRHGAQ DIFTMNSDSI RQTIEKTTST }\end{array}$

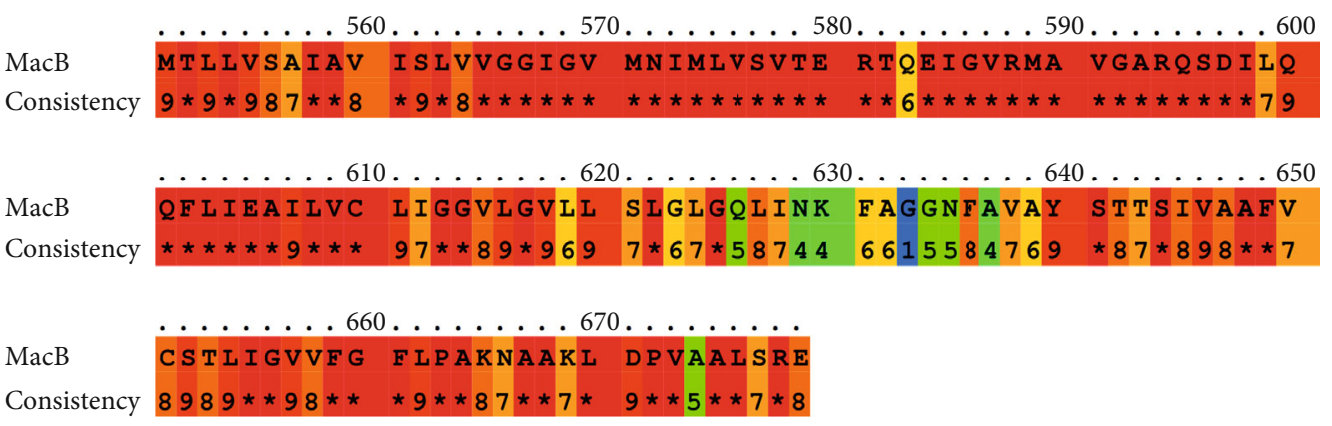

Figure 2: MacB sequence homology with 12 sequences obtained from protein BLAST excluding Acinetobacter. The superposition was performed with the PRALINE programme and adjusted manually. Residues conservation is depicted by blue to red colours. 


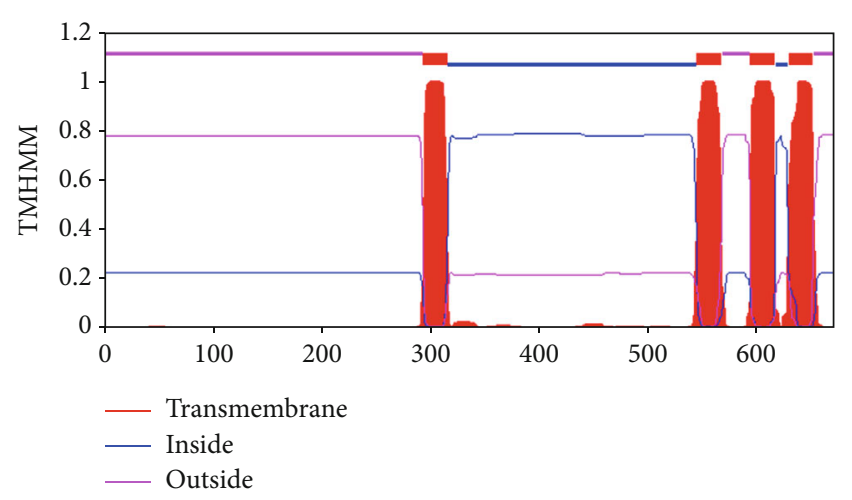

Figure 3: Predicted results of TMHMM server.

\section{Materials and Methods}

2.1. Bacterial Strains and Mice. A. baumannii ATCC 17978 strain was purchased from the American Type Culture Collection (ATCC). Six-week-old female BALB/c mice were purchased from the Experimental Animal Center of Shandong University. All mice were kept in individually ventilated cages. All the animal experiments were approved by the Animal Ethics Committee of Shandong University Qilu Hospital in Qingdao.

2.2. Sequence Alignments. The accession number of $\mathrm{MacB}$ on the National Center for Biotechnology Information (NCBI) is WP_000165901. Nonredundant protein sequences were selected as the database to run Standard Protein BLAST. Firstly, the range of comparison organisms was limited to Acinetobacter (taxid:469). Then, using the same setup, Acinetobacter was excluded from the range of comparison organisms. The sequence with the highest score after blasting was saved in FASTA format and transferred to PRALINE server (http://www.ibi.vu.nl/programs/ pralinewww/). The results of multiple sequence alignment were manually adjusted for a clear display, base residues that were exactly the same and in the same position were indicated by an asterisk and bases that were not exactly the same were numbered. The higher the score, the more conservative the protein sequence.

\subsection{Transmembrane Structure and Signal Peptide Prediction.} Transmembrane regions are generally rigid structures composed of $\alpha$-helices and should be avoided when designing protein vaccines. TMHMM server (http://www.cbs.dtu.dk/ services/TMHMM2.0/) and Octopus server (http://octopus .cbr.su.se/) are classic tools for predicting transmembrane structures. SPLIT (http://split4.pmfst.hr/split/4/) is another website used to predict transmembrane structures. The signal peptide regions predicted by SignalP server (http://www.cbs .dtu.dk/services/SignalP/) were unsuitable as potential antigen epitopes.

2.4. Identification of Functional Residues. The ConSurf server (http://consurf.tau.ac.il/2016/) is a bioinformatics tool for estimating the evolutionary conservation of amino acid positions in a protein molecule based on the phylogenetic relations between homologous sequences. Conserva- tion analysis of positions among members from the same family can often reveal the importance of each position for the protein's structure or function. This information is useful for epitope selection in vaccine development.

This server can also predict exposed and buried residues, which are factors to be considered when selecting antigen epitopes, based on the neural network algorithm.

2.5. Epitope Prediction. The Immune Epitope Database (IEDB) hosts tools to assist in the prediction and analysis of epitopes, including $\mathrm{T}$ and $\mathrm{B}$ cell epitopes. Binding to major histocompatibility complex (MHC) is necessary but insufficient for recognition by $\mathrm{T}$ cells. The tools provided by IEDB can predict IC50 values (Low IC50 = good binders) for peptides binding to specific MHC molecules. The predicted length of $\mathrm{CD}^{+} \mathrm{T}$ cell epitopes bound to MHC class I molecules was set to 9 , and that of $\mathrm{CD}^{+} \mathrm{T}$ cell epitopes bound to MHC class II molecules was set to 15 . The other settings were set in the default mode. Linear B cell epitopes were predicted using Antibody Epitope Prediction server, and BepiPred was selected for prediction. BepiPred predicts the location of linear B cell epitopes using a combination of a hidden Markov model and a propensity scale method. All the selected epitopes were submitted to Sangon Biotech (Shanghai) Co., Ltd for chemical synthesis.

2.6. Establishment of A. baumannii Infection Model in Mice. Mice were infected with $1 \times 10^{5}$ CFU ATCC 17978 strains by intraperitoneal injection. Mouse serum was collected 7 days later for identification of B cell epitopes, and the spleen was isolated for $\mathrm{T}$ cell epitope lymphocyte proliferation test. The $\mathrm{B}$ cell epitope with the strongest antiserum recognition ability and two T cell epitopes with the strongest lymphocyte proliferation ability were selected through the above experiments.

2.7. Construction of Recombinant Antigen Epitope (RAE). The three finally screened antigen epitopes were connected into a RAE through the interval sequence Gly-Ser and then delivered to Sangon Biotech (Shanghai) Co., Ltd for chemical synthesis. 2.8. Immunisation of BALB/c mice was randomly divided into five groups, namely, phosphate-buffered saline(PBS-) negative control group, B cell antigen epitope group, $\mathrm{CD}^{+} \mathrm{T}$ cell antigen epitope group, $\mathrm{CD} 4^{+} \mathrm{T}$ cell antigen epitope group, and RAE group, with 15 mice in each group. Each mouse in each group was thoroughly immunised with complete Freund's adjuvant with $200 \mu \mathrm{g}$ of the target protein. Immunisation was strengthened once on weeks 2, 4, and 6, when it was replaced with incomplete Freund's adjuvant. Serum was collected before each immunisation and on the 14th day after the last immunisation by tail cutting. On the 14th day after the last immunisation, five mice in each group were dissected, and their spleens were isolated for the lymphocyte proliferation test.

2.8. Determination of Serum IgG Antibody. Serum IgG, IgG1, and IgG2a were determined by enzyme-linked immunosorbent assay (ELISA) as described previously [18]. Briefly, antigen epitope proteins were coated in a 96-well plate, 


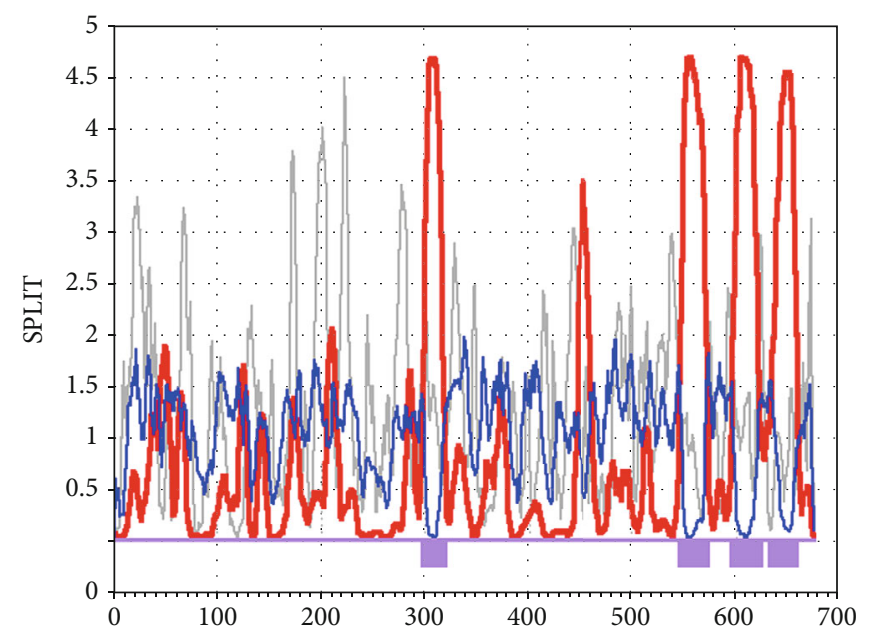

FIgURe 4: Predicted results of SPLIT server.

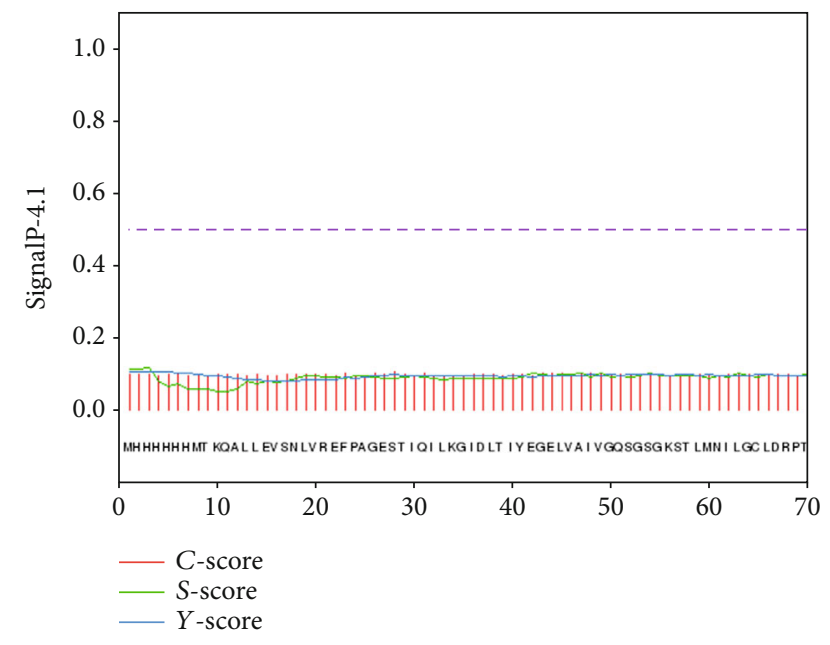

Figure 5: Predicted results of SignalP server.

and after washing and sealing, the serum of each group was added. After washing again, horseradish peroxidaselabelled secondary antibody was added. 3,3',5,5' -Tetramethylbenzidine was used for colour reaction, and optical density (OD) value was measured at $450 \mathrm{~nm}$ by microplating after the reaction was stopped by $\mathrm{H}_{2} \mathrm{SO}_{4}$.

2.9. Cytokine Assay. The removed spleen was prepared as a cell suspension, and $5 \times 10^{5}$ cells/well were added to the 96well plate. Then, the cells were cultured in an incubator at $37^{\circ} \mathrm{C}$ and $5 \% \mathrm{CO}_{2}$. Interleukin (IL) -4 was determined by ELISA at $24 \mathrm{~h}, \mathrm{IL}-10$ at $72 \mathrm{~h}$, and interferon (IFN) $-\gamma$ at $96 \mathrm{~h}$. ConA was used as the positive control.

2.10. Mouse Survival Challenge Experiment. The remaining 10 mice in each group were intraperitoneally injected with $1 \times 10^{7}$ CFU A. baumannii ATCC 17978 strain for the attack test. The morbidity and survival time of each mouse were observed and recorded.

\section{Results}

3.1. Multiple Sequence Alignment Results. The protein database in NCBI showed that MacB protein contained 664 amino acid residues. Through running protein BLAST analysis, 99 homologous sequences were found in Acinetobacter with the defined values of query cover and identity greater than $95 \%$ (Figure 1). Using query cover $>95 \%$ and identity $>65 \%$ as the defined values, protein BLAST analysis was performed in the non-Acinetobacter genera. Twelve protein sequences were finally selected, and they are distributed in Klebsiella pneumoniae, Prolinoborus fasciculus, Pseudomonadales bacterium, Nephila clavipes, and Alkanindiges illinoisensis (Figure 2). When the score of 8 was set as the threshold, $\mathrm{MacB}$ was $98.3 \%$ conservative in Acinetobacter and $61.3 \%$ conservative in nonAcinetobacter.

3.2. Prediction of Transmembrane Structure and Signal Peptides. The prediction results of TMHMM server showed that $\mathrm{MacB}$ contained four transmembrane regions, and the prediction results of SPLIT server were consistent with them. These amino acid residues should be avoided during epitope design. Figures 3 and 4 show the detailed results. SignalP 4.1 server predicted that the $\mathrm{MacB}$ protein sequence contained no potential signal peptide region (Figure 5).

3.3. Prediction of Secondary Structure and Functional Residues. Through the prediction results of ConSurf server, we can screen out the exposed and functional amino acid residues. Only exposed residues can be recognised by corresponding specific antibodies. Functional residues are the key to protein function. The interference of amino acid residue in this region can effectively inhibit its normal function. Figure 6 shows the detailed prediction results.

3.4. Epitope Prediction. Firstly, the software provided by IEDB was used to predict the $\mathrm{B}$ cell, $\mathrm{CD}^{+} \mathrm{T}$ cell, and $\mathrm{CD}^{+} \mathrm{T}$ cell epitopes. Based on the calculation results of each software, the potential epitopes were preliminarily 


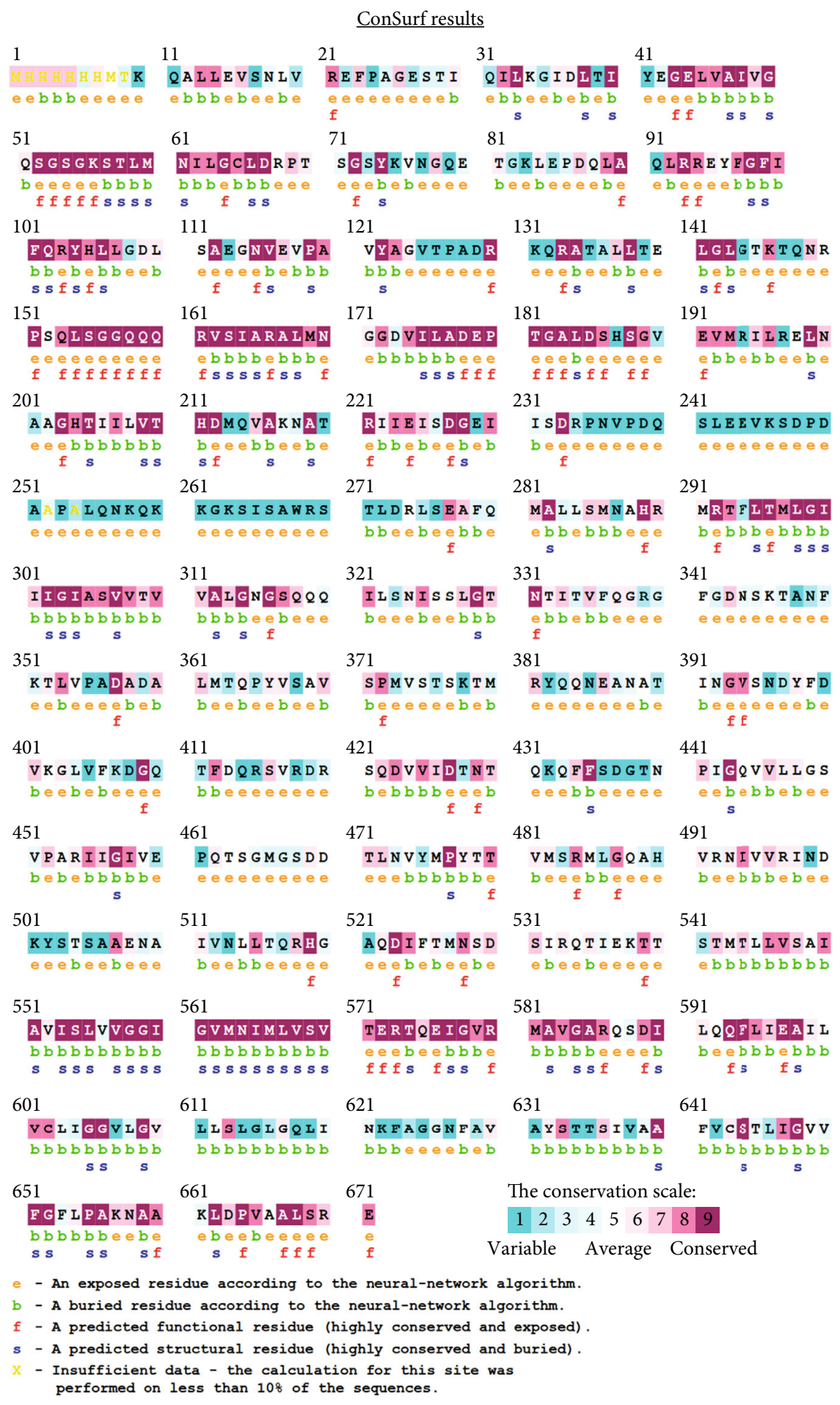

FIGURE 6: ConSurf prediction of functionally and structurally important residues.

selected. Combined with the above prediction results, $6 \mathrm{~B}$ cell epitopes, $3 \mathrm{CD}^{+} \mathrm{T}$ cell epitopes, and $3 \mathrm{CD}^{+} \mathrm{T}$ cell epitopes were finally selected. The details are shown in Table 1. The six predicted B cell epitopes were displayed in the $3 \mathrm{D}$ model of $\mathrm{MacB}$, and the results confirmed that they were all exposed to the surface of the protein structure (Figure 7).
3.5. Experimental Verification of Epitopes. By establishing an animal model of $A$. baumannii infection in mice, serum and spleen cells were collected and isolated, respectively. The result of antibody recognition test shows that epitope 2 has the strongest recognition ability $(P<0.05)$, as shown in Figure $8(a)$. The results of lymphocyte proliferation assay indicated that epitopes 7 and 11 have the strongest stimulation ability $(P<0.05)$, as 
TABle 1: Prediction of epitopes on MacB by bioinformatics.

\begin{tabular}{|c|c|c|c|c|c|c|}
\hline Rank & Type & Start & End & Sequence & Length & Allele \\
\hline Epitope 1 & B cell & 496 & 530 & IVVRINDKYSTSAAENAIVNLLTQRHGAQDIFTMN & 35 & \\
\hline Epitope 2 & B cell & 12 & 46 & KQALLEVSNLVREFPAGESTIQILKGIDLTIYEGE & 35 & \\
\hline Epitope 3 & B cell & 406 & 460 & LVFKDGQTFDQRSVRDRSQDVVIDTNTQKQFFSDGTNPIGQVVLLGSVPARIIGI & 55 & \\
\hline Epitope 4 & B cell & 378 & 393 & TSKTMRYQQNEANATI & 16 & \\
\hline Epitope 5 & B cell & 332 & 372 & TNTITVFQGRGFGDNSKTANFKTLVPADADALMTQPYVSAV & 41 & \\
\hline Epitope 6 & B cell & 69 & 87 & DRPTSGSYKVNGQETGKLE & 19 & \\
\hline Epitope 7 & $\begin{array}{l}\mathrm{CD}^{+} 8 \mathrm{~T} \\
\text { cell }\end{array}$ & 596 & 604 & IEAILVCLI & 9 & $\begin{array}{c}\mathrm{H}-2- \\
\mathrm{Kk}\end{array}$ \\
\hline Epitope 8 & $\begin{array}{c}\mathrm{CD}^{+} 8 \mathrm{~T} \\
\text { cell }\end{array}$ & 99 & 107 & FIFQRYHLL & 9 & $\begin{array}{c}\mathrm{H}-2- \\
\mathrm{Kb}\end{array}$ \\
\hline Epitope 9 & $\begin{array}{c}\mathrm{CD}^{+} 8 \mathrm{~T} \\
\text { cell }\end{array}$ & 477 & 485 & PYTTVMSRM & 9 & $\begin{array}{c}\mathrm{H}-2- \\
\mathrm{Kd}\end{array}$ \\
\hline $\begin{array}{l}\text { Epitope } \\
10\end{array}$ & $\begin{array}{l}\mathrm{CD}^{+} 4 \mathrm{~T} \\
\text { cell }\end{array}$ & 4 & 18 & HHHHMTKQALLEVSN & 15 & $\begin{array}{l}\mathrm{H} 2- \\
\text { IAd }\end{array}$ \\
\hline $\begin{array}{l}\text { Epitope } \\
11\end{array}$ & $\begin{array}{l}\mathrm{CD}^{+} 4 \mathrm{~T} \\
\quad \text { cell }\end{array}$ & 574 & 588 & TQEIGVRMAVGARQS & 15 & $\begin{array}{l}\mathrm{H} 2- \\
\text { IAd }\end{array}$ \\
\hline $\begin{array}{l}\text { Epitope } \\
12\end{array}$ & $\begin{array}{l}\mathrm{CD}^{+} 4 \mathrm{~T} \\
\quad \text { cell }\end{array}$ & 577 & 591 & IGVRMAVGARQSDIL & 15 & $\begin{array}{l}\mathrm{H} 2- \\
\text { IAd }\end{array}$ \\
\hline
\end{tabular}

shown in Figures 8(b) and 8(c), respectively. After connecting the three epitopes, a recombinant epitope was constructed (KQALLEVSNLVREFPAGESTIQILKGIDLTIYEGEGSIEAILVCLIGST QEIGVRMAVGARQS).

3.6. Prediction of T Cell Epitopes. T cell epitopes were predicted by IEDB online server, and the predicted results were ranked by percentile. Low percentile represents good binding. Three $\mathrm{CD}^{+} \mathrm{T}$ cell and three $\mathrm{CD} 4^{+} \mathrm{T}$ cell epitopes were selected by prediction (Table 1; 35-SYAFDKNQL-43, 175IAPYLGFGF-183, 139-KRIGNGDTL-147, 118-WAQGLYIAAGAAY LD -132, 119-AQGLYIAAGAAYLDN-133 and 117-PWAQGLYIAAGAAYL-131).

3.7. Serum IgG Levels of Immunised Mice. ELISA results showed that compared with the PBS control group, all epitope proteins can induce mice to produce specific IgG antibody. Among the three single-antigen epitope groups, B cell epitope 2 showed the highest induction ability. The OD value of the RAE group was significantly higher than that of the single-antigen epitope groups, and the difference was statistically significant $(P<0.05)$. Figure 9 shows the detailed results.

3.8. Cytokine Levels. In the measurement of cytokines in the supernatant of mouse spleen cell culture medium on week 2 after the last immunisation, no significant difference was observed in the IFN- $\gamma$ levels between the control and B cell epitope groups. The levels of IFN- $\gamma$ in the two T cell epitope groups and the RAE group increased, and the difference was statistically significant $(P<0.05)$. The RAE group presented the highest OD value. IL-2 and IL-10 showed no significant differences in each group $(P>0.05)$. Table 2 provides the detailed results.
3.9. Mouse Survival Analysis. The challenge test of A. baumannii infection was performed on the immunised mice on the second week after the last immunisation. The results showed that the mice in the PBS control group could not tolerate the infection, and all died within 6 days. All the epitope protein-immunised groups showed a certain degree of immune protection, among which the mice in the RAE group died within 14 days, and the survival rate was significantly higher than that of the other groups. Figure 10 shows the detailed results.

\section{Discussion}

The drug resistance mechanism of A. baumannii is complicated, and multiple drug resistance mechanisms, including the production of various $\beta$-lactamases, decreased membrane permeability, and increased efflux pump expression, often coexist [19]. Therefore, A. baumannii can show strong resistance to various kinds of antibiotics commonly used in the clinic. CR-Ab infection severely limits the choice of treatment options for clinicians. For patients with severe CR-Ab infection, a combination of multiple advanced antibiotics is often required, which not only requires a long course of treatment but also results in severe toxicity and side effects of the drug [20]. Thus, multidrug-resistant A. baumannii infection poses a huge threat to the lives of patients, especially the critically ill [21].

Given the limited effectiveness of antibiotics, we have committed to develop a bacteriostatic or bactericidal method based on nonantibiotic strategies. Outer membrane proteins play an important role in the survival, drug resistance, and pathogenicity of A. baumannii [22]. Deletion or mutation of key outer membrane proteins can seriously affect the survival and pathogenicity of $A$. 


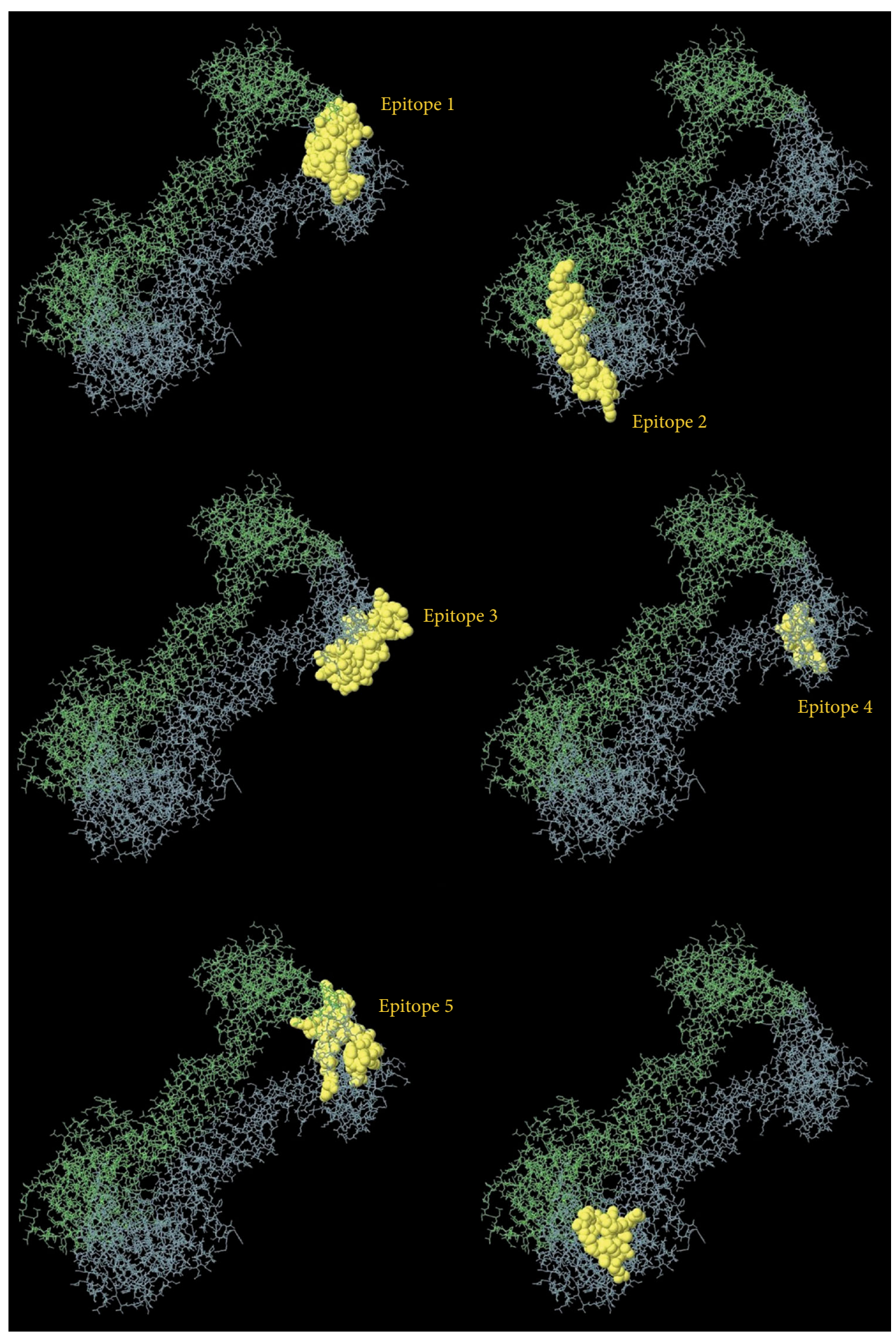

FIGURE 7: Labelled selected B cell epitopes on the 3D structure. The distribution of potential B cell epitopes on MacB is marked with yellow atmos. 


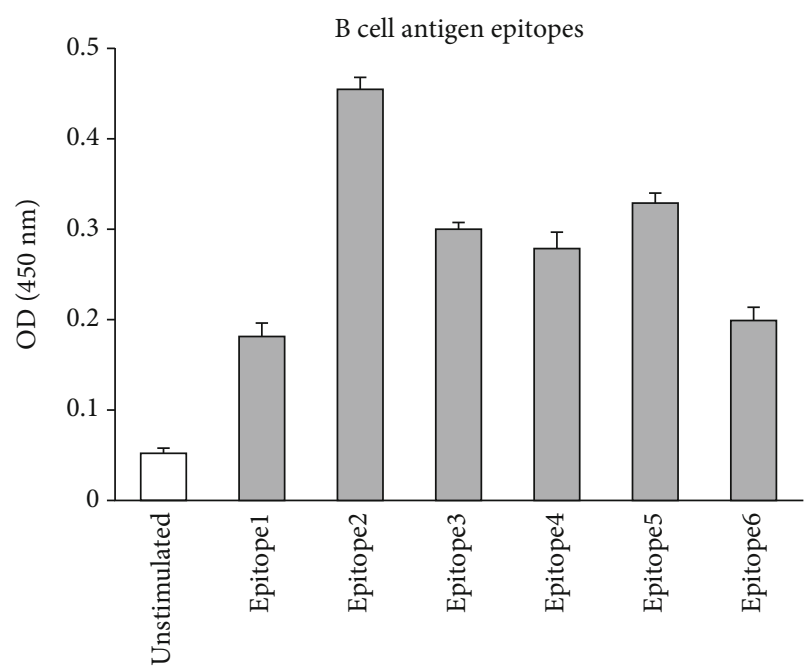

(a)

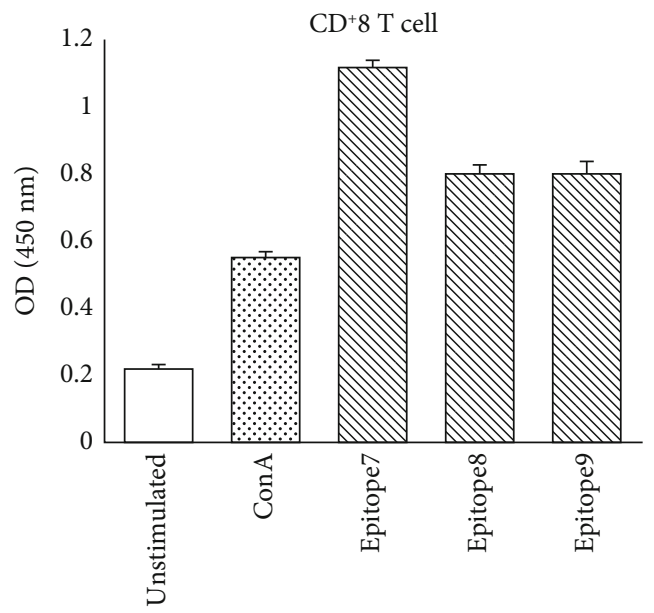

(b)

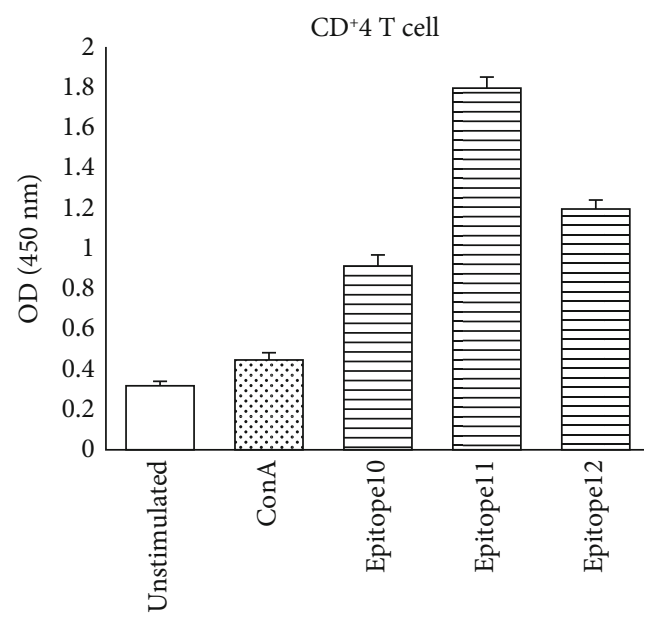

(c)

Figure 8: (a) ELISA was used to screen B cell antigen epitopes; (b) lymphocyte proliferation was used to screen CD8 ${ }^{+} \mathrm{T}$ cell epitopes; (c) lymphocyte proliferation was used to screen $\mathrm{CD} 4^{+} \mathrm{T}$ cell epitopes.

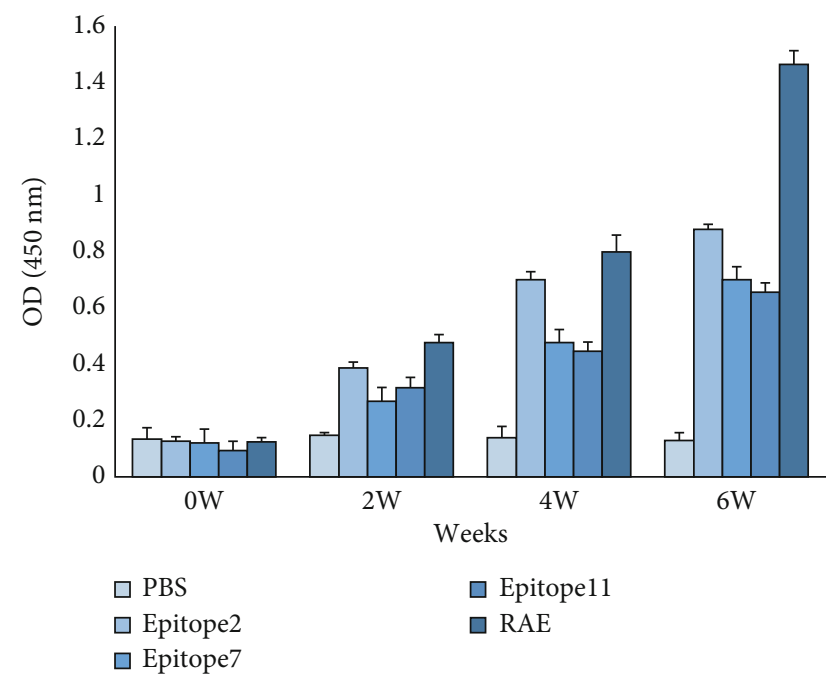

Figure 9: Determination of serum IgG in immunised mice. ${ }^{*} P<$ 0.05 . baumannii [23]. Okada et al. [17] confirmed that the MacA-MacB-TolC tripartite complex is a transmembrane machine and can actively extrude substrates, including macrolide antibiotics, virulence factors, peptides, and cell envelope precursors. These transport activities are driven by ATPase MacB, a member of the ATP-binding cassette superfamily. MacB plays a key role in the material transport of A. baumannii. The upregulation of $\mathrm{MacB}$ gene expression is closely related to the increased resistance of A. baumannii, especially to carbapenem antibiotics and tigecycline $[24,25]$.

In this study, we firstly analysed the protein sequence conservation of $\mathrm{MacB}$. The results show that $\mathrm{MacB}$ is highly conserved within Acinetobacter but has low consistency with the protein sequences of other bacterial species, which indicates the feasibility for the development of protein vaccine based on MacB. Then, through a series of bioinformatics software prediction and molecular biology experiment verification, we finally screened out a $\mathrm{B}$ cell epitope, a $\mathrm{CD} 8^{+} \mathrm{T}$ cell epitope, and a $\mathrm{CD} 4^{+} \mathrm{T}$ cell epitope and reconstructed them 
TABLE 2: Cytokine production in cultures of splenocytes from immunised $\mathrm{BALB} / \mathrm{c}$ mice. ${ }^{*} P<0.05$.

\begin{tabular}{lccc}
\hline \multirow{2}{*}{ Group } & \multicolumn{3}{c}{ Cytokine production (pg/ml) } \\
& IFN- $\gamma$ & IL-2 & IL-10 \\
\hline PBS & $56.04 \pm 2.11$ & $34.11 \pm 1.97$ & $64.32 \pm 7.96$ \\
Epitope 2 & $71.33 \pm 9.98$ & $45.98 \pm 3.28$ & $57.71 \pm 8.30$ \\
Epitope 7 & $405.49 \pm 29.66^{*}$ & $223.64 \pm 21.09^{*}$ & $69.54 \pm 11.01$ \\
Epitope 11 & $571.01 \pm 38.82^{*}$ & $249.79 \pm 34.22^{*}$ & $51.98 \pm 6.12$ \\
RAE & $914.43 \pm 48.29^{*}$ & $397.19 \pm 23.22^{*}$ & $62.77 \pm 9.09$ \\
\hline
\end{tabular}

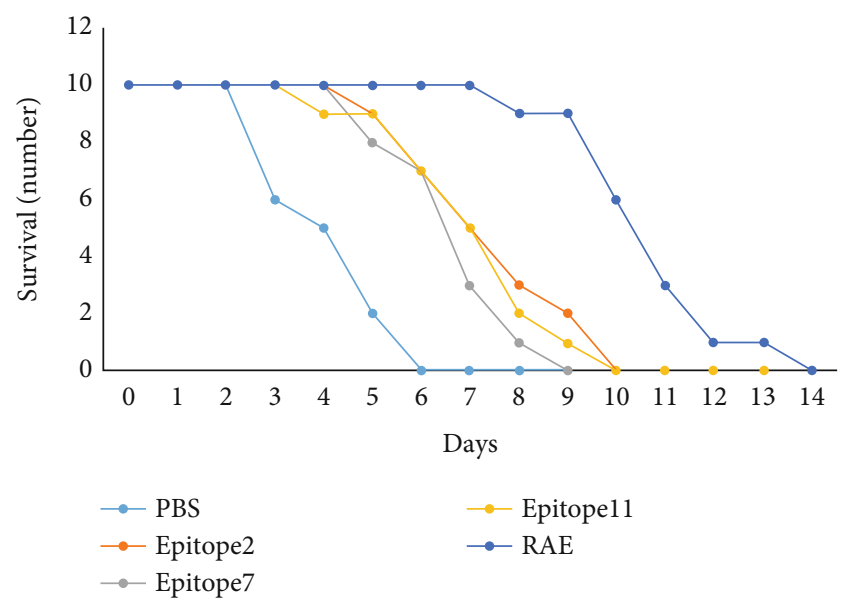

Figure 10: Analysis of mouse survival number.

into a complex antigen epitope (RAE). Immunising mice with epitope proteins, especially RAE, can induce the production of a large number of specific IgG and stimulate lymphocytes to produce a high amount of IFN- $\gamma$. However, the levels of IL-2 and IL-10 showed no increase, suggesting that the antigen epitope protein may stimulate the immune response mediated by Th- 1 cells. Finally, the challenge experiments of A. baumannii infection in immunised mice confirmed that epitope proteins, especially RAE, provided incomplete immunoprotective effects, based on the fact that it extended the survival time of some infected mice, but ultimately failed to prevent death. The results of this study lay the foundation for the development of functional proteins against $A$. baumannii infection.

\section{Data Availability}

The data used to support the findings of this study are available from the corresponding author upon request.

\section{Conflicts of Interest}

All contributing authors declare no conflicts of interest.

\section{References}

[1] A. Howard, M. O'Donoghue, and A. Feeney, "Acinetobacter baumannii: an emerging opportunistic pathogen," Virulence, vol. 3, no. 3, pp. 243-250, 2012.
[2] O. H. F. Raro, S. W. Gallo, C. A. S. Ferreira, and S. D. Oliveira, "Carbapenem-resistant Acinetobacter baumannii contamination in an intensive care unit," Revista da Sociedade Brasileira de Medicina Tropical, vol. 50, no. 2, pp. 167-172, 2017.

[3] S. Pan, X. Huang, Y. Wang et al., "Efficacy of intravenous plus intrathecal/intracerebral ventricle injection of polymyxin B for post-neurosurgical intracranial infections due to MDR/XDR Acinectobacter baumannii: a retrospective cohort study," Antimicrob Resist Infect Control, vol. 7, p. 8, 2018.

[4] J. Gao, Y. Zou, Y. Wang et al., "Breath analysis for noninvasively differentiating Acinetobacter baumannii ventilatorassociated pneumonia from its respiratory tract colonization of ventilated patients," Journal of Breath Research, vol. 10, no. 2, article 027102, 2016.

[5] M. Jain, A. Sharma, M. K. Sen, V. Rani, R. Gaind, and J. C. Suri, "Phenotypic and molecular characterization of Acinetobacter baumannii isolates causing lower respiratory infections among ICU patients," Microbial Pathogenesis, vol. 128, pp. 75-81, 2019.

[6] T. Ballouz, J. Aridi, C. Afif et al., "Risk factors, clinical presentation, and outcome of Acinetobacter baumannii bacteremia," Frontiers in Cellular and Infection Microbiology, vol. 7, p. 156, 2017.

[7] L. Chuang and L. Ratnayake, "Overcoming challenges of treating extensively drug-resistant Acinetobacter baumannii bacteraemic urinary tract infection," International Journal of Antimicrobial Agents, vol. 52, no. 4, pp. 521-522, 2018.

[8] D. J. deFreitas and J. P. McCabe, "Acinetobacter baumanii meningitis," Journal of Spinal Disorders \& Techniques, vol. 17, no. 2, pp. 115-116, 2004.

[9] S. Helal, M. el Anany, D. Ghaith, and S. Rabeea, "The role of MDR-Acinetobacter baumannii in orthopedic surgical site infections," Surgical Infections, vol. 16, no. 5, pp. 518-522, 2015.

[10] M. Jiang, Y. Mu, N. Li, Z. Zhang, and S. Han, "Carbapenemresistant Acinetobacter baumannii from air and patients of intensive care units," Polish Journal of Microbiology, vol. 67, no. 3, pp. 333-338, 2018.

[11] L. C. Antunes, P. Visca, and K. J. Towner, "Acinetobacter baumannii: evolution of a global pathogen," Pathogens and Disease, vol. 71, no. 3, pp. 292-301, 2014.

[12] U. Theuretzbacher, "Global antimicrobial resistance in Gramnegative pathogens and clinical need," Current Opinion in Microbiology, vol. 39, pp. 106-112, 2017.

[13] C.-A. Liang, Y. C. Lin, P. L. Lu, H. C. Chen, H. L. Chang, and C. C. Sheu, "Antibiotic strategies and clinical outcomes in critically ill patients with pneumonia caused by carbapenemresistant Acinetobacter baumannii," Clinical Microbiology and Infection, vol. 24, no. 8, pp. 908.e1-908.e7, 2018.

[14] J. Vashist, V. Tiwari, A. Kapil, and M. R. Rajeswari, “Quantitative profiling and identification of outer membrane proteins of beta-lactam resistant strain of Acinetobacter baumannii," Journal of Proteome Research, vol. 9, no. 2, pp. 1121-1128, 2010.

[15] R. Debroy, S. K. Miryala, A. Naha, A. Anbarasu, and S. Ramaiah, "Gene interaction network studies to decipher the multi-drug resistance mechanism in Salmonella enterica serovar Typhi CT18 reveal potential drug targets," Microbial Pathogenesis, vol. 142, article 104096, 2020.

[16] P. P. Yewale, K. B. Lokhande, A. Sridhar et al., "Molecular profiling of multidrug-resistant river water isolates: insights into 
resistance mechanism and potential inhibitors," Environmental Science and Pollution Research International, vol. 27, no. 22, pp. 27279-27292, 2020.

[17] U. Okada, E. Yamashita, A. Neuberger, M. Morimoto, H. W. van Veen, and S. Murakami, "Crystal structure of tripartitetype ABC transporter MacB from Acinetobacter baumannii," Nature Communications, vol. 8, no. 1, article 1336, 2017.

[18] G. Zhao, X. Song, X. Kong et al., "Immunization with Toxoplasma gondii aspartic protease 3 increases survival time of infected mice," Acta Tropica, vol. 171, pp. 17-23, 2017.

[19] P. He, S. W. Li, and X. Y. Wan, "The mechanism of drug resistance in Acinetobacter baumannii and updates of development in novel antibiotics," Zhonghua Nei Ke Za Zhi, vol. 56, no. 10, pp. 777-780, 2017.

[20] B. A. Evans, A. Hamouda, and S. G. B. Amyes, "The rise of carbapenem-resistant Acinetobacter baumannii," Current Pharmaceutical Design, vol. 19, no. 2, pp. 223-238, 2013.

[21] E. Warde, E. Davies, and A. Ward, "Control of a multidrugresistant Acinetobacter baumannii outbreak," The British Journal of Nursing, vol. 28, no. 4, pp. 242-248, 2019.

[22] P. Nowak and P. Paluchowska, "Acinetobacter baumannii: biology and drug resistance - role of carbapenemases," Folia Histochemica et Cytobiologica, vol. 54, no. 2, pp. 61-74, 2016.

[23] D. Nie, Y. Hu, Z. Chen et al., "Outer membrane protein A (OmpA) as a potential therapeutic target for Acinetobacter baumannii infection," Journal of Biomedical Science, vol. 27, no. 1, article 26, 2020.

[24] M. F. Lin, Y. Y. Lin, and C. Y. Lan, "The role of the twocomponent system BaeSR in disposing chemicals through regulating transporter systems in Acinetobacter baumannii," PLoS One, vol. 10, no. 7, article e0132843, 2015.

[25] M. F. Lin, Y. Y. Lin, C. C. Tu, and C. Y. Lan, "Distribution of different efflux pump genes in clinical isolates of multidrugresistant Acinetobacter baumannii and their correlation with antimicrobial resistance," Journal of Microbiology, Immunology, and Infection, vol. 50, no. 2, pp. 224-231, 2017. 